\title{
The determinants of South Korean outward FDI in Russia: a partial least square (PLS) analysis
}

\author{
Han-Sol Lee*, and Pengfei Liu \\ Peoples' Friendship University of Russia, 117198, Moscow, Russia
}

\begin{abstract}
The significance of economic cooperation between South Korea and Russia is growing due to the new foreign policies of the two countries: the New Northern policy of South Korea, and the Pivot to East of Russia. Thereby, in this study, we investigated the determinants of South Korean outward FDI in Russia based on the time-series data for the period 19932017 to draw policy implications. To overcome the issues of multicollinearity and the small number of observations in an ordinary least square (OLS) function, we employed a partial least square (PLS). The result of PLS analysis indicated that GDP (+) and inflation (-) are statistically significant out of the 7 explanatory variables in our model. But, as the coefficient of inflation was too small, it is also hard to be defined as a significant factor. While, the difference of GDP per capita, freedom index, the nominal exchange rate, natural resource, and trade openness are determined as statistically insignificant. From the result, we found that South Korean outward FDI in Russia is predominantly purposed with marketseeking.
\end{abstract}

Keywords: Foreign Direct Investment, Korean Economy, Russian Economy, South Korea-Russia economic cooperation

\section{Introduction}

An unprecedented stark economy growth and a deregulation of foreign investment laws on private enterprises in South Korea gave impetus to cross-border activities. Since the first foreign direct investment of KODECO in Indonesia for the mining development, South Korean outward FDI has grown consistently, and rapidly. Nowadays, South Korea is a strong source of overseas investment. From 2018, South Korean outward FDI has surpassed 50 us dollars, which is the ninth largest in the world. Aside that, however, the distribution of South Korean outward FDI is highly biased towards a few countries: in 2018, 38.2\% of Korean outward FDI was concentrated on USA (21.7\%), China (9.6\%), and Hong Kong (7.1\%) [1]. Due to those skewed investments in a few countries, South Korean economy is highly vulnerable to global economic shocks.

\footnotetext{
* Corresponding author: li-kh@ rudn.ru
} 
In this vein, the diversification of foreign partnerships has been a political agenda in the recent decade. The Post-Soviet countries, the Northern countries from the point of South Korea, has been considered as a land of opportunities to integrate Eurasia as a common market based on the completion of logistics and energy networks. In this line, in 2013, and 2017, the South Korean government announced "Eurasia Initiatives" and "New Northern Policy", respectively, purposed with the development of partnerships with the Post-Soviet countries, Mongolia, and three Northern provinces of China. Meanwhile, the economic slowdown of Russia since 2014 spurred the cooperation with emerging Asian countries as a means of a breakthrough in economic growth. Which led the Russian government to address the "Pivot to Asia" policy to enhance the underdeveloped Siberian and Far Eastern economy. Despite those growing political importance, the previous studies to investigate the determinants of South Korean outward FDI are either outdated or limited to China as a recipient country [2-6]. Thus, in this research paper, we would like to demonstrate the specific-factors driving South Korean outward FDI in Russia. This paper is composed as follows. In the second section, we carried out the literature review on the modern FDI theories, and the recent empirical studies of the determinants of FDI in transition economies. The third and fourth section present the data information and results of PLS analysis. Finally, we suggest policy implications in conclusions.

\section{Theoretical underpinnings and empirical studies}

In the modern era, Hymer pioneered the FDI theory in the basis of the imperfect market. According to Hymer's theory, foreign firms are initially disadvantaged to compete with domestic firms in culture, language, legal system and consumer's preferences. Thereby, foreign firms decide to establish international operations only if they hold firm-specific advantages, superior enough to create profits as offsetting those disadvantages in international market [7]. Later, Kindleberger developed Hymer's theory and explained the motivations of direct investment based on monopolistic power, an elaborated concept of a firm-specific factor in Hymer's theory. According to the theory, a great opportunity to create monopoly profits is the significant determining factor to spur direct investment of firms [8].

Institutional FDI fitness theory articulated by Wilhems and Witter also demonstrated the attraction, absorption, and retainment of FDI on the basis of locational determinants. The theory is especially aimed to clarify the reasons behind skewed distribution of FDI among recipient countries based on the following four pillars from the most primary to the strongest institutions: Society \& Culture- the oldest, the most primary, but, the most complicated above all the other kinds of institutions; Education- human capital quality to communicate, interpret, and implement the FDI operations; Market- economic and financial aspects of the institutions in terms of the level of physical (i.e. machinery) and financial (i.e. credit) capital; Government- the political, legislative, and regulative aspects of institutions. A specific order in impact factors does not mean a separate operation of the four institutional pillars. However, instead, those factors are closely interrelated, shape and influence on one another in a different from [9].

Meanwhile, Buckley and Casson articulated internalization theory identifying the motivations of direct investment in terms of reduction of unnecessary transaction costs. The theory is constructed based on the following assumptions: (a) the imperfect market condition, (b) the firms' pursuit of profit maximization, (c) the occurrence of high transaction costs in intermediary products or technology during the market exchange due to the assumption (a), (d) the internalization of foreign markets to bypass unnecessary external costs, and (e) the creation of MNCs [10].

Later, Dunning introduced a comprehensive theory of FDI by overcoming the drawbacks of previous theories, which failing to fully explain why (ownership and internalization), and 
where (location) firms select for FDI. Dunning emphasized the interrelatedness of those three factors. FDI occurs only when those three conditions are satisfied [11]. Although it is notable that the eclectic paradigm is the most recognized FDI theory, it also faced criticisms like the other FDI theories owing to the inapplicability to some cases emerged in changing global economic environment. As Shin questioned, his theory failed to explain the outward direct investment from less developed countries without ownership advantages [12].

On the other hands, based on those theoretical backgrounds, multiple scholars conducted empirical studies on a specific. In our study, we focused on the recent articles to investigate the determinants of FDI in transition economies. Popovici carried out fixed effects panel data analysis during 1994-2013 to explore the determinants of inward FDI in the 11 Central and Eastern European (CEE) countries. The results indicated that during the transition period from 1994-2003, the foreign investors are attracted by institutional quality, growth potential, and openness to confirm whether they can really sell their products. While, after the transition of economy from 2004-2013, investments are mainly driven by labor force and cheap wage to increase production efficiency [13]. In the follow-up study of Salahodjaev, Yuldashev, and Omanbayev on the ex-communist countries from 1990-2015, the institutional quality, for instance, political stability, and rule of law are also defined as significant to attract inward FDI. Besides, it further demonstrated that FDI in the Post-communist countries aim to the market-seeking [14].

Meanwhile, some research papers are concentrated to the case of the Commonwealth of Independent States (CIS). Shukurov investigated the driving forces of inward FDI in CIS countries for the period 1995-2010. The study confirmed that the previous FDI stock, market size, and natural resource induce foreign investments, while macro economic instability deters foreign investments [15]. Besides, the study of Akhmetzaki and Mukhamediyev on the EEU members (Kazakhstan, Belarus, the Russian Federation, Armenia, Kyrgyzstan), and 5 other countries (Azerbaijan, Tajikistan, Moldova, Georgia, Ukraine) during 1993-2015 again confirmed the significance of market size like the previous studies, and added infrastructure development and secondary education enrollment as significant factor to increase FDI [16]. To conclude, the empirical studies on the transition economies commonly demonstrated the market-seeking as the main driving factors of FDI inflows. While, it is likely that the significant of the other factors vary in the cases.

\section{Data specification}

To conduct regression analysis, we built balanced time series from 1993-2017. The dependent variable is the logarithm of FDI inflows (million US\$) from Korea to Russia, which is acquired from the Export-Import Bank of Korea [1]. Based on the literature review, 7 explanatory variables are selected, as shown in Table 1.

Table 1. Description of explanatory variables.

\begin{tabular}{|c|c|c|}
\hline Variables & Description & Source \\
\hline LGDP $_{\mathrm{t}}$ & $\begin{array}{c}\text { Log of GDP (current price, billion \$) } \\
\text { in year } t\end{array}$ & IMF [17] \\
\hline LGGDP $_{\mathrm{t}}$ & $\begin{array}{c}\text { Log of subtracting value per capita } \\
\text { GDP of Russia from that of South } \\
\text { Korea (\$) in year } \mathrm{t}\end{array}$ & IMF [17] \\
\hline LFREE $_{\mathrm{t}}$ & $\begin{array}{c}\text { Log of the sum of political rights and } \\
\text { civil liberties ratings in year t }\end{array}$ & Freedom House [18] \\
\hline LRESOU $_{\mathrm{t}}$ & $\begin{array}{c}\text { Log of total natural resources rents } \\
\text { (\% of GDP) in year t }\end{array}$ & World Bank [19] \\
\hline
\end{tabular}




\begin{tabular}{|c|c|c|}
\hline LINFLA & Log of inflation rate (\%) in year t & IMF [17] \\
\hline LOPEN $_{\mathrm{t}}$ & $\begin{array}{c}\text { Log of trade volumes (\% of GDP) in } \\
\text { year } \mathrm{t}\end{array}$ & $\begin{array}{c}\text { Korean International } \\
\text { Trade Association [20] }\end{array}$ \\
\hline NER $_{\mathrm{t}}$ & $\begin{array}{c}\text { Nominal exchange rate (local } \\
\text { currency/USD) in year } \mathrm{t}\end{array}$ & $\begin{array}{c}\text { Federal Reserve Bank of } \\
\text { St. Louis [21] }\end{array}$ \\
\hline
\end{tabular}

Source: Composed by the author.

$L G D P_{t}$ is an approximation of market size. The larger market size provides the higher potential demands. Thereby, the expected sign of the coefficient is $(+)$.

$L G G D P_{t}$ is an approximation of difference of individual standard living and wage rate. Lower GDP per capita than South Korea provides a possibility to utilize cheap labor force. Therefore, the expected sign of the coefficient is $(+)$.

$L F R E E_{t}$ is an approximation of institutional quality to measure a social stability. Thereby, the expected sign of the coefficient is $(+)$.

$\operatorname{LRESOU}_{t}$ is an approximation of natural resource endowments. Conventionally, natural resources have played a significant role to induce FDI in Russia. Therefore, the expected sign of the coefficient is $(+)$.

LINFLA $A_{t}$ is an approximation of economic instability. The high inflation rate indicates the economic turbulence. Thus, the expected sign of the coefficient is (-).

$L_{O P E N}$ is an approximation of trade/market openness. The transition process toward marketization has been defined as a significance factor to induce FDI in the post-soviet countries. Thereby, the expected sign of the coefficient is $(+)$.

$N E R_{t}$ is an approximation of production cost efficiency. The currency depreciation of host countries brings relative cost reductions for foreign investors. Thereby, the expected sign of the coefficient is (-).

Where $\beta_{0}$ is a constant; $\varepsilon_{t}$ is an error-term in year $\mathrm{t}$.

\section{Empirical results and discussions}

We carried out regression analysis based on the times series data of Korean outward FDI in Russia for the period 1993-2017. Minimum, maximum, mean, and standard deviations (SD) of the data are described in Table 2 . For the data, we conducted four different tests to clarify the issue of autocorrelation, and multicolliearity.

Table 2. Descriptive statistics.

\begin{tabular}{|c|c|c|c|c|c|}
\hline Variables & N & Minimum & Maximum & Mean & S.D \\
\hline LFDI & 25 & -0.08 & 2.63 & 1.65 & 0.69 \\
\hline LGDP & 25 & 2.30 & 3.36 & 2.87 & 0.36 \\
\hline LGGDP & 25 & 3.81 & 4.32 & 4.06 & 0.13 \\
\hline LFREE & 25 & 0.85 & 1.11 & 0.98 & 0.09 \\
\hline LINFLA & 25 & 0.57 & 2.94 & 1.28 & 0.58 \\
\hline LRESOU & 25 & 0.59 & 1.34 & 1.10 & 0.20 \\
\hline LOPEN & 25 & 1.53 & 1.74 & 1.68 & 0.05 \\
\hline EXRATE & 25 & 0.01 & 1.01 & 0.11 & 0.21 \\
\hline
\end{tabular}

First, Durbin-Watson test and Breusch-Godfrey test are conducted to confirm the nonpossession of autocorrelation in the time series. If a value of Durbin-Watson statistics equals to 2.0 , it indicates no autocorrelation in the time series. A value of 1.80 statistics, highly close 
to 2.0 , is obtained from the Durbin-Watson test. The p-value is 0.128 . Which indicates that the null hypothesis, residuals are not autocorrelated from an ordinary least square (OLS) function, is accepted at $10 \%, 5 \%$, and $1 \%$ level. The result of Breusch-Godfrey test also demonstrated the non-issue of autocorrelation at $10 \%, 5 \%$, and $1 \%$ level, as the p-value is 0.6424 .

However, in terms of multicollinearity, as described in Table 3, it is elucidated that multiple variables are highly correlated as that of Pearson's correlation coefficient are over \pm 0.5 .

Table 3. Pearson's correlation of explanatory variables.

\begin{tabular}{|c|c|c|c|c|c|c|c|}
\hline Variables & LGDP & LGGDP & LFREE & LINFLA & LRESOU & LOPEN & NER \\
\hline LGDP & $\mathbf{1 . 0 0}$ & & & & & & \\
\hline LGGDP & 0.56 & $\mathbf{1 . 0 0}$ & & & & & \\
\hline LFREE & 0.81 & 0.71 & $\mathbf{1 . 0 0}$ & & & & \\
\hline LINFLA & -0.76 & -0.55 & -0.81 & $\mathbf{1 . 0 0}$ & & & \\
\hline LRESOU & 0.41 & 0.26 & 0.67 & -0.55 & $\mathbf{1 . 0 0}$ & & \\
\hline LOPEN & 0.42 & 0.49 & 0.68 & -0.82 & 0.43 & $\mathbf{1 . 0 0}$ & \\
\hline NER & -0.50 & -0.42 & -0.61 & 0.82 & -0.50 & -0.86 & $\mathbf{1 . 0 0}$ \\
\hline
\end{tabular}

Source: Composed by the author.

Besides, the result of the VIF test demonstrated the clear concern of multicollinearity among factors, as the VIF of LFREE, LINFLA, and LOPEN exceeds 10 . The variance inflation factor (VIF) of LGDP and NER, which is between 5 and 10, also present high correlations (Table 4). Thereby, the result confirms that the data is inappropriate to run OLS regression.

Table 4. The result of variance inflation factor (VIF) test.

\begin{tabular}{|c|c|c|c|c|c|c|}
\hline LGDP & LGGDP & LFREE & LRESOU & LINFLA & LOPEN & NER \\
\hline 8.57 & 2.59 & 14.87 & 3.55 & 10.03 & 11.10 & 6.19 \\
\hline
\end{tabular}

Source: Composed by the author.

To overcome the multicollinearity, we chose a partial least square (PLS). PLS regression has been widely used to deal with the concern of multicollinearity by reducing predictors with a set of uncorrelated components and performing least squares on these components instead of the original data. Contrary to OLS, PLS liberates from multicollinearity issue, even if the number of explanatory variables increases infinitely [22]. In addition, PLS is a popular method to resolve the problem of the small number of observations. In general, it is difficult to apply the conventional multiple regression analysis, if the minimum number of observations does not satisfy the number of observations $(\mathrm{N}) \geq 5 \mathrm{P}$ (explanatory variable) [23, p.7]. On the contrary, PLS enables to apply a multiple regression with a limited number of observations even in the case when there are more explanatory variables than the numbers of observations [24]. In this vein, to elucidate the statistical significance of all 7 variables based on limited 25 observations with multicollinearity issue, PLS is selected.

A projection of the optimal number of a latent factor is the first step of PLS regression. For this, we referred the values of (adjusted) root mean square error of prediction (RMSEP) to measure the model's explanatory power in the different number of a latent factor. The lower value of RMSEP presents the better accuracy of the model in prediction. If RMSEP consistently shows the decreasing tendency, then the decision should be based on the 
difference of decrease. If decrease of RMSEP becomes insignificant from a certain number of a latent factor, the model should be designed based on that number of a latent factor [25]. As described in Table 5, we selected 2 latent factors when the value of (adjusted) RMSEP is the lowest, 4.0. Two latent factors explain $91.43 \%$ of variance of 7 predictor variables (cumulative proportions of $\mathrm{X}$ variance). The explanatory power of response variable (cumulative proportions of $\mathrm{Y}$ variance) is $73.70 \%$, which indicates that the model fits the data well.

Table 5. The selection of latent factors.

\begin{tabular}{|c|c|c|c|c|}
\hline $\begin{array}{c}\text { Latent } \\
\text { factor }\end{array}$ & $\begin{array}{c}\text { Cumulative } \\
\text { proportions of } X \\
\text { variance }\end{array}$ & $\begin{array}{c}\text { Cumulative } \\
\text { proportions of } \\
\text { variance }\end{array}$ & RMSEP & $\begin{array}{c}\text { Adjusted } \\
\text { RMSEP }\end{array}$ \\
\hline 1 & 82.10 & 52.27 & 0.51 & 0.51 \\
\hline 2 & 91.43 & 73.30 & 0.40 & 0.40 \\
\hline 3 & 94.13 & 75.06 & 0.47 & 0.46 \\
\hline 4 & 97.85 & 75.30 & 0.48 & 0.47 \\
\hline 5 & 97.99 & 75.66 & 0.60 & 0.58 \\
\hline 6 & 99.50 & 75.66 & 0.63 & 0.61 \\
\hline 7 & 100.00 & 75.92 & 0.62 & 0.60 \\
\hline
\end{tabular}

Source: Composed by the author.

The significance of predictor variables in PLS regression is determined by the value of Variable Importance in the Projection (VIP), instead of p-value in OLS regression. If the VIP value of a predictor variable is less than 0.8 , it can be considered as statistically insignificant [26]. If the VIP value is close to or greater than 1 , it is identified as a highly significant predictor.

Table 6. The result of PLS regression.

\begin{tabular}{|c|c|c|c|c|c|c|c|c|}
\hline Variables & Coefficient & \multicolumn{7}{|c|}{ VIP changes affected by Latent Factors } \\
\hline Intercept & -3.050 & 1 & 2 & 3 & 4 & 5 & 6 & 7 \\
\hline LGDP & 1.671 & 1.686 & 1.761 & 1.740 & 1.737 & 1.734 & 1.733 & 1.731 \\
\hline LGGDP & 0.086 & 0.288 & 0.245 & 0.317 & 0.319 & 0.319 & 0.319 & 0.335 \\
\hline LFREE & 0.128 & 0.309 & 0.261 & 0.263 & 0.265 & 0.302 & 0.305 & 0.305 \\
\hline LINFLA & -0.035 & 1.920 & 1.783 & 1.762 & 1.760 & 1.756 & 1.755 & 1.753 \\
\hline LRESOU & -0.327 & 0.253 & 0.488 & 0.506 & 0.520 & 0.521 & 0.520 & 0.520 \\
\hline LOPEN & -0.115 & 0.085 & 0.168 & 0.166 & 0.167 & 0.192 & 0.204 & 0.205 \\
\hline NER & 0.217 & 0.469 & 0.572 & 0.643 & 0.643 & 0.641 & 0.641 & 0.644 \\
\hline
\end{tabular}

Source: Composed by the author.

Table 6 presents the result of PLS regression including the VIP values for 1-7 latent factors, and the coefficient of explanatory variables in the case of 2 latent variables. The interpretation of the result is based on the 2 latent factors. Both LGDP and LINFLA are turned out highly significant explanatory variables as the VIP values surpassed 1, but the coefficient signs showed opposite results. LGDP is positively correlated with LFDI: a $1 \%$ increase in GDP will promote FDI by $1.671 \%$. While, the coefficient sign of LINFLA showed negative: a $1 \%$ increase in inflation will lead to $0.035 \%$ decrease in FDI. Considering that the coefficient is highly close to 0 , the impact of LINFLA on LFDI is not impressive despite the highest VIP values. Meanwhile, the other 5 variables (LGGDP, LFREE, LRESOU, 
LOPEN, NER) are identified as a statistically insignificant. Therefore, it can conclude that LGDP is the only significant variable in terms of both VIP value and coefficient.

\section{Conclusions}

This paper investigated the determinants of South Korean outward FDI in Russia for the period 1993-2017 by employing the PLS regression analysis, as considering the growing importance of the economic cooperation between South Korea and Russia under the new foreign policies of the two countries. The result of our empirical study confirmed the statistical significance of market size (LGDP), which indicates that South Korean outward FDI strongly aims market-seeking. On the other hand, the other six explanatory variables are turned out insignificant due to either a small coefficient (LINFLA) or VIP $<0.8$ (LGGDP, LFREE, LRESOU, LOPEN, NER). It is likely that the market-seeking of South Korean outward FDI in Russia is predominant enough to take a certain degree of risk caused by low institutional quality, and macro economic instability. Considering that South Korean outward FDI is purposed with labor seeking in general, it is also notable that cheap labor cost does not hold any impact on that in Russia. Besides, unlike the conventional foreign investments in Russia, natural resources is turned out an irrelevant variable to attract South Korean outward FDI in Russia.

It has been criticized that Northern policy of South Korea does not bear impressive fruits: from 2017-2019, South Korean outward FDI in Russia was below 100 million us dollars. South Korean investors are passive to enter in Russian market despite that Russia is becoming one of the most attractive destinations for foreign investment, as doing business ranking by World Bank jumped from 124th (2010) to 28th (2019). Some insisted that the unfavorable macro environment mainly caused by Western Sanctions deters South Korean investment in Russia. However, it is not persuasive enough to explain the ungrowing investments, considering that the participant countries in the Sanctions like Germany are consistently investing in Russia, and besides South Korea does not participate in the Sanctions. From our study, it turned out that the utmost motivations of South Korean investors in Russia is market expansion. In reality, South Korean investments in Russia are mainly done by small and medium sized companies in manufacturing, services, and retail and wholesale, while the key industries that the Korean government addressed for the New Northern policy are only sectors requiring massive capitals, for instance, railways, energy, and arctic route. Thus, the policy implication of our research paper is that during the initial stage, the government should implement policies to enhance small capital investments as a first priority. Based on those database in private and public sectors, the investment should be expanded to a bigger sector in a way to satisfy other motivations of foreign investment, namely resource-seeking, assetseeking, and efficiency-seeking.

Besides, it should be recognized that despite the statistically acceptable conduct of PLS regression, still the small number of observations is a limitation to obtain a good result. Because, the regression result based on a limited time series is more likely to show the statistical significance of only the most powerful explanatory variable despite the importance of the other variables in the reality. In this vein, in the follow-up study, it is recommendable to conduct the regression analysis with group of countries, which share common economic, social, and political characteristic with Russia to attain results that are more robust.

\section{References}

1. Export-Import bank of Korea. Retrieved March 10, 2020, from https://www.koreaexim.go.kr/site/main/index002. 
2. H. Lee, The destination of outward FDI and the performance of South Korean multinationals. Emerging Markets Finance and Trade, 46(3), 59-66 (2010)

3. B.-G. Ha, S. Lee, The Structure and Determinants of Outward Foreign Direct Investment of Korea. Legislation and Policy Studies, 3(2), 75-98 (2011) [In Korean]

4. S.W. Kim, Determinants of Korean FDI in China -1992 2008-. The Journal of Northeast Asian Economic Studies, 23(1), 109-136 (2011) [In Korean]

5. Oh-Suk Yang, Meng-Di Wang, The Locational Determinants of Korean Companies' FDI in China: Focusing on Market-seeking and Knowledge-seeking Motivation. Journal of International Trade \& Commerce, 13(6), 267-293 (2017)

6. Eun-hee Kim, Seung-hun Yu, An Analysis on the Determinants of Korea's FDI Location Choice in China. Journal of Korea Research Association of International Commerce, 19(1), 1-28 (2019) [In Korean]

7. S.H. Hymer, The international operation of national firms: a study of direct foreign investment (MIT Press, Cambridge, MA, United States, 1976)

8. C.P. Kindleberger, American business abroad (Yale University Press, New Haven, CT, United States, 1969)

9. S.K. Wilhelms, M.S.D. Witter, Foreign direct investment and its determinants in emerging economies (United States Agency for International Development, Bureau for Africa, Office of Sustainable Development,1998)

10. P.J. Buckley, and M. Casson, The Future of the Multinational Enterprises (Macmillan, London,1976).

11. J. H. Dunning, Toward an eclectic theory of international production: Some empirical tests. Journal of International Business Studies, 11 (1980)

12. S. Shin, A Critical review of the FDI theories. Journal of Asia-Pacific studies, 5, 179211 (1998)

13. O.C. Popovici, Assessing FDI determinants in CEE countries during and after transition. The Annals of the University of Oradea, 24(1), 113-122 (2015)

14. R. Salahodjaev, O. Yuldashev, B. Omanbayev, What drives foreign direct investment into post-communist economies? MPRA, University Library of Munich, Germany, 73277 (2016)

15. S. Shukurov, Determinants of FDI in transition economies: the case of CIS countries. Journal of International and Global Economic Studies, 9(1), 75-94 (2016)

16. Ye. Zh. Akhmetzaki, B. M. Mukhamediyev, FDI determinants in the Eurasian economic union countries and Eurasian economic integration effect on FDI inflows. Ekonomika regiona [Economy of Region], 13(3), 959-970 (2017)

17. IMF. Retrieved March 10, 2020, from https://www.imf.org/external/datamapper/datasets/WEO.

18. Freedom House. Retrieved March 10, 2020, from https://freedomhouse.org/.

19. World Bank. Retrieved March 10, 2020, from https://data.worldbank.org/.

20. Korean International Trade Association. Retrieved March 10, 2020 from http://www.kita.org/.

21. Federal Reserve Bank of St. Louis. Retrieved March 10, 2020, from https://www.stlouisfed.org/.

22. Jeong Gwangseop. Presumed Influence Factors of Decision-Making of Mega-Projects. The Board of Audit and Inspection, 19, 91-124 (2012). 
23. Yun-Hong Lee, Joo-Hyung Lee, An Analysis on the Affecting Factor of Subway's Service Satisfaction Level Using the PLS Regression Analysis - Focused on the Subway Users in Seoul. Journal of Transport Research), 19(4), 1-16 (2012) [In Korean]

24. G.S. Jeong, G.Y. Park, J.H. Lee, Presumed Influence Factors of User Satisfaction of Seoul Digital Industrial Complex using PLS-Regression Model. Journal of the Korea Academia-Industrial cooperation Society, 15(6), 3931-3943 (2014)

25. Yun-Hong Lee, Joo-Hyung Lee, An Analysis on the Affecting Factor of Subway's Service Satisfaction Level Using the PLS Regression Analysis - Focused on the Subway Users in Seoul. Journal of Transport Research, 19(4), 1-16 (2012) [In Korean]

26. Svante Wold, Exponentially weighted moving principal components analysis and projections to latent structures. Chemometrics and Intelligent Laboratory Systems, 23(1), 149-161 (1994) 